This is a self-archived version of an original article. This version may differ from the original in pagination and typographic details.

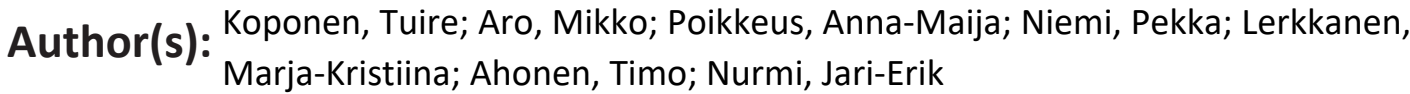

Title: Comorbid Fluency Difficulties in Reading and Math : Longitudinal Stability Across Early Grades

Year: 2018

Version: Accepted version (Final draft)

Copyright: (c) The Authors 2018

Rights: In Copyright

Rights url: http://rightsstatements.org/page/InC/1.0/?language=en

Please cite the original version:

Koponen, T., Aro, M., Poikkeus, A.-M., Niemi, P., Lerkkanen, M.-K., Ahonen, T., \& Nurmi, J.-E. (2018). Comorbid Fluency Difficulties in Reading and Math : Longitudinal Stability Across Early Grades. Exceptional Children, 84(3), 298-311. https://doi.org/10.1177/0014402918756269 
Comorbid Fluency Difficulties in Reading and Math: Longitudinal Stability across Early Grades 


\begin{abstract}
We examined the prevalence of comorbidity of dysfluent reading and math skills longitudinally in a representative sample $(N=1,928)$ and the stability of comorbid and single difficulties from grades first to fourth. The findings indicated that half the children who showed very low performance in one skill also evidenced low or very low performance in the other. Comorbid difficulties had somewhat higher prevalence in third and fourth graders than in first and second graders. The stability of comorbid difficulties was found to be established from grade two onwards, but the stability of single difficulties increased steadily across grades. Overall, the findings emphasize the relatively strong stability of comorbid difficulties after the second grade and underscore the need for close monitoring of, and support for, both skills as opposed to just one.
\end{abstract}

Keywords: comorbidity, reading fluency, math fluency 


\section{Comorbid Fluency Difficulties in Reading and Math: Longitudinal Stability across}

\section{Early Grades}

Reading and math constitute basic academic skills that, along with spelling and writing, form the foundation for academic learning. Difficulties in fluent reading (i.e., slow and erroneous serial decoding) hamper learning both within and outside school. Similarly, the effortless retrieval of facts from memory in everyday calculation tasks and the learning of more advanced math are likely to be compromised when basic arithmetic skills are dysfluent.

Reading difficulties (RD) and math difficulties (MD) are known to co-occur more often than expected with regard to the prevalence of the respective single deficits (e.g., Landerl \& Moll, 2010). Thus, difficulties in one domain clearly increase the risk of difficulties in the other. Moreover, there are major challenges regarding comorbid difficulties: these are often more resistant to early support and intervention than single deficits (Fuchs, Fuchs, \& Prentice, 2004; Fuchs et al., 2010; Powell, Fuchs, Fuchs, Cirino, \& Fletcher, 2009), and co-occurring reading and math problems have been found to increase the risk for a range of behavioral problems (Lin et al., 2013). Comorbid reading and math deficits can have serious long-term effects on achievement later in life (Murray, Goldstein, Nourse, \& Edgar, 2000), such as the narrowing of social and occupational prospects in adulthood.

There is little knowledge on the prevalence of comorbid fluency difficulties in reading and math and their stability across time in the early school years. Relatively few studies have examined the prevalence of combined reading and math disabilities in population-based samples (Badian, 1999; Dirks, Spyer, van Lieshout, \& de Sonneville, 2008; Lewis, Hitch, \& Walker, 1994; Landerl \& Moll, 2010; Moll, Kunze, Neuhoff, Bruder, \& Schulte-Körne, 2014). Only one research group (Landerl \& Moll, 2010; Moll et al., 2014) specifically examined the prevalence of comorbid fluency issues. To the best of our knowledge, no studies have addressed the stability of such difficulties across the early school years using a 
longitudinal design and representative age-cohort sample. Previous prevalence studies employed cross-sectional designs and combined several age groups in different phases of skill development.

Nevertheless, the importance of understanding the nature and development of comorbid fluency difficulties is widely acknowledged; both intervention (Fuchs et al., 2010; Powell et al., 2009) and longitudinal studies have examined the development of reading and math skills in children with comorbid or single difficulties (e.g., Jordan, Kaplan, \& Hanich, 2002; Lin et al., 2013; Vukovic \& Siegel, 2010). Results support the view that reading and math skills are closely related: students displaying persistent math difficulties (MD) from first to fourth grade also scored lower in phonological decoding (Vukovic \& Siegel, 2010). However, findings also suggest that the influence of comorbidity on the development of reading and math skills may not be symmetrical. There is evidence showing that children with comorbid (MD/RD) difficulties developed more slowly in math as compared to children with MD only, whereas children with RD and comorbid (RD/MD) difficulties developed in reading at similar rate (Jordan et al., 2002).

The present study expands the previous knowledge by examining the prevalence and stability of comorbid reading and math fluency difficulties in a large-scale representative Finnish follow-up sample in grades first through fourth.

\section{Differences in Prevalence Rates and Outcome Measures}

According to Landerl and Moll (2010), comorbidity estimates range from $17 \%$ to $70 \%$ for children with a math disability who also show evidence of having difficulty with reading and $11 \%$ to $59 \%$ for children with a reading disability who have difficulty with math. The use of multiple cutoff scores, exclusion criteria, and operationalization of target skills affects the magnitude of prevalence estimates and hampers the interpretation of contradictory findings (Dirks, 2008). 
Applying a categorical classification (i.e., using a cutoff based on a dichotomized variable) rather than a dimensional approach to define and diagnose learning difficulties has recently been criticized (e.g., Branum-Martin, Fletcher, \& Stuebing, 2012). Very few, if any, attempts have been documented using other methods to operationalize the co-occurrence of difficulties. A small number of studies have addressed this criticism with the application of several cutoff criteria and analyses of the effects on the prevalence estimates of RD and MD (e.g., Landerl \& Moll, 2010; Moll et al., 2014). Similarly, we applied two cutoff criteria (at or below the $16^{\text {th }}$ and $7^{\text {th }}$ percentiles, representing -1.0 and -1.5 standard deviations [SD], respectively) and their combinations. This approach is supported by findings that suggest the existence of qualitative differences in developmental trajectories among children with MD of different levels of severity. Murphy, Mazzocco, Hanich, and Early (2007), for instance, found a faster rate of growth in math performance for children with low performance $\left(11^{\text {th }}-25^{\text {th }}\right.$ percentiles) than for the very low performing group (at or below the $10^{\text {th }}$ percentile).

Differences in how the reading and math skills are measured may have affected reported prevalence rates. Relatively few studies have addressed the influence of different types of operationalization. Dirks and colleagues (Dirks et al., 2008) showed that different outcome measures for reading disabilities, for example spelling and reading and reading comprehension instead of word recognition, led to selection of other children.

Differences in prevalence rates may also be due to whether the criterion variable is based on a measure of accuracy or fluency. Some researchers have used a combination of accuracy- and fluency-based measures depending on the skill under study (Dirks et al., 2008; Lewis et al., 1994). We used fluency measures as key criterion variables for both math (arithmetical calculation) and reading tasks. This choice is particularly relevant in languages with transparent orthographies (the letter-to-sound correspondences are bisymmetrically regular, as with Finnish) because beginning readers of such languages achieve a high 
accuracy level after the first semester of reading instruction even when their word decoding speed is still slow (e.g., Aro \& Wimmer, 2003; Seymour, Aro, \& Erskine, 2003). Fluency is also a major problem in MD (Geary, 1993). For example, adequate accuracy rates but clear fluency problems were found in simple calculations by 9- to11-year-old children with specific language impairment (Koponen, Mononen, Räsänen, \& Ahonen, 2006).

Comorbidity estimates are likely to vary by age and phase of skill development, but there is a dearth of explicit and relevant information because previous studies typically had cross-sectional designs deploying several age groups (Dirks et al., 2008; Landerl \& Moll, 2010; Lewis et al., 1994; Moll et al., 2014) instead of longitudinal designs following up on sufficiently large samples. In the early stages of skill acquisition, serial phonemic assembly and counting-based strategies are also common among children of typical achievement, whereas reliance on such elementary strategies at ten years or older leads to compromised fluency and suggests an absence of the expected developmental shift from decoding to automatized word reading or from counting-based strategies to memory retrieval.

\section{Prior Studies of Prevalence of Comorbidity}

Table 1 summarizes the procedures and prevalence estimates reported in four prior population-based studies that used test-based measures and distinct criteria to identify deficits in math skills and reading. The prevalence of comorbid dysfluency difficulties varied from $22 \%$ to $64 \%$. The age groups also differed between the studies, and the cutoff criterion ranged from the $25^{\text {th }}$ to the $7^{\text {th }}$ percentile ( $\mathrm{SD}=-0.7--1.5$ ). These variations in samples and criteria present challenges for comparing the observed comorbidity rates and deciphering the underlying reasons. For instance, Dirks et al. (2008) and Lewis et al. (1994) applied an accuracy-based measure in one skill and a fluency-based measure in the other, whereas the more recent studies (Landerl \& Moll, 2010; Moll et al., 2014) applied fluency-based 
measures in both reading and math skills. Therefore, it is impossible to make a direct comparison between these studies.

In recent studies in the German language context (Landerl \& Moll, 2010; Moll et al., 2014), the prevalence of comorbid dysfluency was reported to vary from $22 \%$ to $41 \%$, and the prevalence rates for co-occurrence of $\mathrm{MD}$ and $\mathrm{RD}$ were lower (22-31\% for $-1.5 \mathrm{SD}$ and $34-41 \%$ for $-1 \mathrm{SD}$ ) with more stringent cutoff criteria. The observed/expected ratio of comorbid difficulties, by contrast, was higher when more stringent cutoff criteria were applied: comorbidity was 2.6 times higher than would have been expected based on the occurrence estimates of both difficulties with the more lenient -1 SD cutoff, and 4.2 times higher when the -1.5 SD criterion was used (Moll et al., 2014). In both abovementioned studies, cross-sectional data were used and the samples consisted of several age groups, as was also the case in Dirks et al. (2008) and Lewis et al. (1994). Thus, more studies of comorbidity in reading and math dysfluency are needed to clarify the effects of age and phase of skill development.

\section{The Present Study}

This study extends the previous literature on comorbid RD and MD via a longitudinal design to examine the prevalence rate of dysfluency in reading and math, the effects of different cutoff criteria and age groups on the prevalence rate, and the stability of comorbid problems from the first to the fourth grade. Reading fluency was defined as fast and accurate reading (see Pikulski \& Chard, 2005), and math fluency was operationalized as fast and accurate arithmetical calculation with single-digit and multidigit numbers (see Koerte et al., 2016). Of particular interest is whether the co-occurrence of dysfluency in reading and math is similar at the early phase (from grades 1 to 2 ) of skill development as compared to later and more consolidated phases of development (from grades 3 to 4). Co-occurrence of MD and RD dysfluency was expected to be more stable in the later than the early phase (when 
strategies are still evolving and automatization of basic skills is under way). This study addressed the following three research questions.

Research question 1. To what extent does the prevalence of comorbid reading and math fluency difficulties vary according to the cutoff criteria and grade level? More specifically, we examined the following questions. To what extent do difficulties in reading and math fluency co-occur (RQ 1.1)? To what extent do the prevalence rates for comorbid problems depend on the cutoff criteria (RQ 1.2)? Does the prevalence rate for comorbid problems vary by age (RQ 1.3)?

Research question 2. What are the effects of the severity levels of the difficulties on comorbidity rates? More specifically, we examined the following questions. To what extent do children with low performance (identified with a more lenient criterion, the $16^{\text {th }}$ percentile or -1.0 SD) in math fluency have comorbid fluency difficulties in reading compared to children with very low performance (identified using a more stringent criterion, the $7^{\text {th }}$ percentile or -1.5 SD) in math fluency (RQ 2.1)? To what extent do children with low performance in reading fluency have comorbid fluency difficulties in math compared to children with very low performance in reading fluency (RQ 2.2)?

Research question 3. How stable are comorbid problems in reading and math fluency across first through fourth grades (RQ 3)?

\section{Method}

\section{Participants}

This is part of a longitudinal study (Lerkkanen et al., 2006) in which 1,928 Finnish children (916 girls; age at kindergarten entry: $M=74.0 \pm 3.6$ months) were followed from kindergarten to fourth grade (ages 6-11). The sample was recruited from four municipalities in Finland (two in central, one in western, and one in eastern Finland). The sample contained the whole age cohort of children in three municipalities and approximately half the age cohort 
in the fourth. The majority (80\%) of participating children came from two-parent families, $10 \%$ from single-parent families, $8 \%$ from blended families, and $2 \%$ from families in which the parents were divorced and the child lived in two homes. The sample was representative of the Finnish population in terms of the highest household educational level, according to the Official Statistics of Finland (2007). In 7\% (general population, 6\%) of families, the parents had not completed education beyond comprehensive school (compulsory education up to the completion of grade 9); $31 \%$ (general population, 30\%) completed upper secondary education (senior high school or vocational school, grades 10-12); 36\% (general population, 35\%) had a bachelor's or vocational college degree (3-year education at a college or university); and $26 \%$ (general population, 29\%) had a master's degree (5-year university education) or higher (Metsäpelto et al., 2015). The participants were all native speakers of Finnish and had no documented intellectual or sensory deficits. Parents had provided written consent for their child's participation. This study adheres to the recommendations of the National Advisory Board on Research Ethics.

The Finnish primary education system differs from that of North America and many other European countries with respect to later age of school entry (age seven), uniform quality of both instruction and teacher qualifications across the country, and thus, small differences between the schools in academic achievement (see PISA, 2015), autonomy of schools and teachers in selecting instructional practices and materials based on general curriculum guidelines without reliance on any external inspection system. Finnish kindergarten education and comprehensive school are free of charge and almost exclusively offered by public schools. Systematic instruction of decoding skills and calculation with symbols does not start before the beginning of grade 1 (National Core Curriculum for Comprehensive School, 2004). All Finnish first graders are exposed to synthetic phonicsbased literacy instruction, with an explicit focus on learning to decode syllables and words, 
and parallel support for development of fluency and comprehension. Word-level decoding reaches a high level of accuracy for most grade 1 students after the fall. In grade 1 math instruction, the main focus is on number concepts and basic arithmetical skills (addition and subtraction with single-digit numbers), algebra, geometry, and measurement. The majority of Finnish teachers base their math teaching on textbooks from commercial publishers that are not subject to official approval but must adhere to national curriculum guidelines.

Students with special needs are typically integrated into regular classrooms. Part-time special education is amply provided from grade 1 onwards for students who need support for learning in one or several subjects. A smaller proportion of children attend special classes in mainstream education schools, and only children who cannot be adequately served within mainstream schools attend special education schools. Children from special education schools were not included in the study sample.

\section{Measures and Procedures}

The present data comprise longitudinal assessments at four time points between the first and fourth grades: spring of grade 1 (Time 1 [T1; $n=1,928$ ), Grade 2 (Time 2 [T2]; $n=$ 1,906), grade 3 (Time 3 [T3]; $n=1,927$ ), and grade 4 (Time 4 [T4]; $n=1,874$ ). The attrition rate was low, ranging from $1 \%$ to $3 \%$ from one grade level to the next. Missing data were unrelated to learning difficulty status (reading difficulties, RD; math difficulties, MD; reading and math difficulties, RD/AD; or typical achievement TA) in each grade $(p>.05)$. Reading and math skills were assessed using standard group-administered tests. All tests were administered at the schools by trained research assistants. Most of the children with learning problems in the sample did not have a formal diagnosis because it is not required in order to be eligible for learning support in Finnish schools. The provision of part-time special education is flexible, and the decision to provide extra support is based on the pedagogical assessment and expert evaluation of teachers. 
Math fluency. Math fluency was assessed using the group-administered arithmetic test (Aunola \& Räsänen, 2007). At the outset, the test consists of 28 items that contained 14 addition tasks (e.g., $2+1=$ ?; $3+4+6=$ ?) and 14 subtraction tasks (e.g., $4-1=$ ?; $20-2$ $-4=$ ?). The test has a three-minute time limit. The difficulty of the items increases steadily. Final scores are the total number of correct responses within the time limit (the maximum score was 28 points).

Reading fluency. A sentence verification task (A Finnish adaptation of the TOSREC; Test of Silent Reading Efficiency and Comprehension; Wagner et al., 2009) was used as a measure of reading fluency. The Finnish version (Lerkkanen \& Poikkeus, 2008) consists of 60 sentences (i.e., "An apple is blue"; "Candy is usually sweet”) with simple semantic content and linguistic form. Students are asked to read and decide whether the sentences are true or not. The test has a three-minute time limit. Final scores are based on the number of correct responses within the time limit ( $\min / \max 0 / 60)$.

\section{Data Analysis}

First, descriptive statistics were calculated for each measure (Table 2) and crosstabulated associations were analyzed using the chi-square test. Second, the prevalence rates and the observed/expected ratios (Table 3) were calculated for comorbid difficulties at each grade using two different cutoff criteria of deficits (at or below the $16^{\text {th }}$ percentile and at or below the $7^{\text {th }}$ percentile, comparable to the $1 \mathrm{SD}$ or $1.5 \mathrm{SD}$ below mean that were used as criteria in previous studies by Landerl and Moll, 2010 and Moll et al., 2014). Third, to examine the effect of the severity of difficulties on comorbidity rates, both arithmetic and sentence reading fluency variables were divided into three categories:

1) Typical performers (above the $16^{\text {th }}$ percentile);

2) Low performers (performance at or below the $16^{\text {th }}$ percentile, but above the $7^{\text {th }}$ percentile; corresponding to $-1.0 \mathrm{SD})$, and 
3) Very low performers (at or below the $7^{\text {th }}$ percentile; corresponding to $-1.5 \mathrm{SD}$ ).

Analyses were carried out separately for both math and reading skills (Table 4) in order to compare the comorbidity rates in groups with a) low vs. very low skills in math, and b) low vs. very low skills in reading and low or very low performance in both domains. The confidence intervals (CI) for prevalence estimates were calculated using the Wilson score interval (Wilson, 1927). Fourth, to examine the stability of comorbid and single difficulties, the proportions of students with stable problems (from first to second, from second to third, and from third to fourth grade) were calculated for comorbid and single difficulties, respectively (Table 5). Comorbid problems were defined to show stability if a child with very low performance (at or below the $7^{\text {th }}$ percentile) in both skills at time 1 continued to have very low performance in both skills, or very low performance in at least one skill and low performance (at or below the $16^{\text {th }}$ percentile) in the other skill. Single problems were defined to show stability when a child showing very low performance in one domain (at or below the $7^{\text {th }}$ percentile) and typical performance (above the $16^{\text {th }}$ percentile) in the other continued to have very low (at or below the $7^{\text {th }}$ percentile) or low performance (at or below the $16^{\text {th }}$ percentile) in the same domain and remained typical in the other domain.

Finally, to extend the analysis from using purely dichotomous measures to continuous variables, scatter plots are presented (see Figure 1) to show how the children were classified to have comorbid difficulties (according to the strict criterion) at one time point performed in reading and math fluency during the following years.

\section{Results}

\section{Descriptive Statistics}

Table 2 presents the means and standard deviations of the measures. The chi-square test revealed a significant dependency between reading and math fluency at each grade: the value varied between 209.4 and $289.2(p<.001)$ across grades. The adjusted residuals 
indicated that the column proportions for severe comorbid difficulties (at or below the $7^{\text {th }}$ percentile) differed from the proportions expected by chance: the adjusted standardized residuals increased steadily across grades and varied between 10.4 and 14.0, indicating more cases than expected with the lowest performance in both skills.

\section{Prevalence of Comorbid Fluency Difficulties}

Our first aim was to examine the extent to which difficulties in reading and math fluency co-occur (RQ1.1), whether the prevalence rates depend on the cutoff criteria used (RQ1.2), and whether the comorbidity rates vary across grades 1 to 4 (RQ1.3).

Table 3 shows that prevalence estimates were $27 \%-46 \%$ and that the observed/expected ratios were 2.3-5.4. The first column indicates that about $40 \%$ of children (35-46\%) with performances below the $16^{\text {th }}$ percentile in one domain also performed below the $16^{\text {th }}$ percentile in the other domain. Comorbid difficulties were more than twice as common as would be expected to occur by chance (observed/expected ratio 2.3-2.9). Second, using the more stringent criterion in both reading and math (lowest $7^{\text {th }}$ percentile in both skills), about one third of children (27-37\%) were found to have comorbid difficulties. Comorbid cases were observed four to five times more often than expected by chance (observed/expected ratio 4.6-5.4). There were no major differences or systematic changes in the prevalence estimates across the grades for the $16^{\text {th }}$ percentile as the cutoff criterion. For the strict criterion, comorbidity rates were slightly higher in the third and fourth grades (36$37 \%)$ than in the first or second grades (27-32\%). However, the prevalence rates across the grades overlapped once the confidence intervals were taken into account (+/- 7\%-9\%).

Second, it was compared how the severity of fluency difficulties in math (i.e. having low versus very low performance level), is associated with having difficulties in reading fluency (low or very low performance) and vice versa (Table 4). Very low performance in math overlapped in half the cases (50-57\%), with low or very low performance in reading 
resulting in a stronger risk for comorbid difficulties than low performance in math (comorbidity $30 \%-40 \%$ ). The same was true when comparing low and very low performance in reading. A child with low performance in one domain was more likely to show a typical (above the $16^{\text {th }}$ percentile) than an atypical (at or below the $16^{\text {th }}$ percentile) performance in the other domain. In contrast, a very low performance in one domain was more likely to be associated with atypical than typical performance in the other skill.

\section{Stability of Comorbid and Single Fluency Difficulties}

Our second aim was to examine the stability of comorbid fluency difficulties from first grade onward (RQ2).

Table 5 shows that the stability of comorbid difficulties increased after second grade and remained relatively stable from second to third and third to fourth grade. Seventy-three percent of second graders with very low reading and in math fluency had comorbid difficulties one year later, with either very low performance in both skills or very low performance in one skill and low performance in the other. The corresponding estimate from first to second grade was $41 \%$.

Table 5 also shows that the stability of single difficulties increased by grade. However, single difficulties were found to be less stable than comorbid difficulties, and there were differences in the stability of single deficits between the domains and grade levels. Difficulties in reading fluency were more stable than difficulties in math fluency in the early grades: $42 \%$ of first graders who had very low performance in word reading fluency remained at the same level in second grade, whereas the corresponding stability rate for math fluency difficulty was only $23 \%$. Math fluency difficulties, however, were shown to be as stable as RD at the later grades: $62 \%$ of the third graders with very low math fluency also had low or very low performance one year later. The stability estimate for reading fluency was at the same level (59\%). Figure 1 presents scatterplots of the performance in later years of 
children identified having comorbid difficulties at one time point. The findings are in line with those based on purely categorical variables, showing that children identified in first grade to have comorbid difficulties are more likely to have subsequent typical performance in one or both domains than children identified in the second or third grade.

\section{Discussion}

Our study had three aims. The first was to examine the prevalence of comorbidity in reading and math fluency difficulties using two possible cutoff criteria. As an extension to previous studies, we examined the prevalence rates longitudinally, across the first four school years, to determine whether comorbidity prevalence rates change along with age. The second aim was to examine the effects of the severity of the difficulties on comorbidity rates. The third aim was to study the stability of comorbid and single difficulties across the early grades (i.e., to what extent children with difficulties at one time point will continue to show difficulties later).

Our study contributes to existing literature in four ways. First, we found that the severity of the learning problem plays a pivotal role in comorbid reading and math problems: a severe difficulty in one domain clearly increased the likelihood of problems in the other. Second, comorbidity rates vary according to grade level. Third, comorbid difficulties are more stable across time than single difficulties. Fourth, in contrast with MD, RD appear to become stable earlier, at the end of Grade 2.

Landerl and Moll (2010) and Moll et al. (2014) used similar cutoff criteria with German-speaking children and found corresponding prevalence estimates for comorbid difficulties: more than twice as often as expected by chance with a lenient criterion and four to five times more often with a stricter criterion. The age of the children and the associated phase of skill development had some impact on the prevalence rates. The prevalence estimates for different ages mostly overlapped with a more lenient criterion, but with the 
stringent criterion, there was a trend for the prevalence of comorbidity to increase from first and second grade to third grade, along with the observed/expected ratios. Previous studies of comorbidity in reading and math fluency (Lander \& Moll, 2010; Moll et al., 2014) used cross-sectional data with samples covering from two to four consecutive years of age, thus not being able to provide prevalence rates at different phases of skill development. In contrast, our finding suggests that among very low performers, reading and math fluency problems overlap especially in the developmental phase where direct retrieval instead of serial processing would characterize typical skill development. This is in line with other recent findings that children with dyslexia perform worse than controls in arithmetic efficiency test, thus suggesting that poor fact retrieval in children with dyslexia is likely a consequence of deficits in the language system affecting both reading and math fluency (Koerte et al., 2016).

Our findings further indicated that about half the children with very low performance in one domain also showed low or very low performance in the other. In the case of low performance, the risk for comorbid difficulties was lower $(30 \%-40 \%)$. This result emphasizes that findings of higher comorbidity when using a lenient cut-off criterion (-1SD or $16^{\text {th }}$ percentile) should not be interpreted as reflecting a larger overlap of milder difficulties as compared to more severe difficulties. In contrast, our findings support the view that a student with very low performance in one domain is more likely to have difficulties in the other (Vukovic \& Siegel, 2010). The higher comorbidity percentages with the lenient criterion (see Landerl \& Moll, 2010; Moll et al., 2014) are likely because several different comorbidity profiles are included, such as very low skill in both domains, low performance in both domains, very low performance in reading and low in math, and very low performance in math and low in reading. Our findings have important practical implications, underlining the need for a more comprehensive view of skills in both domains when planning support. 
Previous studies (Landerl \& Moll, 2010; Moll et al., 2014) utilized cross-sectional data, precluding a stability analysis of difficulties. The third aim of this study was a unique attempt to investigate the stability of comorbid and single difficulties across the early grades. Somewhat lower stability estimates were found in the earlier than in the later grades. The stability estimate for comorbidity was $41 \%$ for the transition from first to second grade, but it increased noticeably from second to third grade $(73 \%)$ and remained similar until fourth grade. For single difficulties, the stability estimates were distinctly lower, with differences between the domains. In the early grades, RD were more stable than MD, but from third to fourth grade, there were no differences, with stability at $59 \%$ in reading and $62 \%$ in math.

The higher stability for comorbid RD and MD might be related to a constellation of underlying cognitive deficits. It has been suggested that children with comorbid difficulties in reading and math have a wider set of cognitive deficits, including use of language and numbers (Landerl, Göbel, \& Moll, 2013; Vukovic \& Siegel, 2010), and thus fewer means to compensate for or overcome their issues in comparison to children with single difficulties whose cognitive deficits may be narrower. Another possibility is that a shared cognitive deficit underlies comorbid fluency difficulties and is challenging to overcome. For example, naming speed deficits have been found to be resistant to interventions (de Jong \& Vriedlink, 2004). It is also known to be an underlying deficit in RD (e.g., Bowers, Sunshet, \& Golden, 1999; Wolf \& Bowers, 1999) and has recently been proposed as an underlying deficit in math fluency difficulties (Koponen et al., 2006; Waber, Wolff, Forbes, \& Weiler, 2000; for a metaanalysis, see Koponen, Georgiou, Salmi, Leskinen \& Aro, 2016).

\section{Limitations}

As with all studies, this one has certain limitations that should be considered when interpreting the current findings. First, reading and math skills were assessed in a group 
situation that might not be optimal for all children. Moreover, only one math test was used, which did not allow for the analysis of different types of math subskills or arithmetical knowledge, such as fact retrieval and procedural calculation. Second, the orthography of the Finnish language is highly transparent. Almost all children become good decoders and accurate readers during the first grade (Seymour, Aro, \& Wimmer, 2003), and reading difficulties are characterized more by fluency problems than poor accuracy. This must be taken into account when generalizing the results to less transparent orthographies, especially English, where reading accuracy develops markedly slower than in most other languages with alphabetic orthographies. It is likely that a larger part of the variance in reading fluency tasks among English-speaking children is due to individual differences in reading accuracy. This variation between languages indicates that despite similar cutoff criteria in reading fluency tasks, it is possible to have qualitatively different groups in reading. Cross-linguistic comparisons are needed to clarify the influence of the orthography on comorbidity rates and their stability.

Third, differences in educational systems should be considered. Because systematic instruction in reading and math does not begin before school entrance in the Finnish educational system, different results might have been obtained in other educational and societal contexts. The variance in reading and math skills during the early grades may be influenced by the experience level of Finnish students compared to countries where formal instruction begins earlier. This contrast can be especially influential for the stability of difficulties, which may reach the constant level later in Finland than in countries where children are exposed to formal education earlier.

Fourth, demographic and socioeconomic differences are rather small in Finland compared to many other countries (see PISA, 2015), and measures such as parents' educational level have typically explained a rather small amount of variance in academic 
skills. A free-of-charge and public education system can at least partially equalize different learning outcomes that arise from differences in children's socioeconomic backgrounds. More cross-cultural prevalence studies are needed to determine whether the prevalence rates of comorbid fluency difficulties found in Finnish and German students are universal and what factors could explain possible differences. Such differences should be considered especially when examining the factors underlying comorbid difficulties.

\section{Conclusions}

This study showed that severity of difficulties influences the co-occurrence of difficulties in reading and math fluency. Children with very low performance in either skill had an increased probability of very low or low performance in the other as well. Comorbid difficulties were found to be more stable than single difficulties and, at least based on findings in Finnish children, comorbidity seems to establish after the second grade. Close monitoring of skill development is needed from the beginning of schooling for children who manifest dysfluent basic skills. In light of the present results, second grade appears to be especially important and relevant for fluency development and detection of a risk for problems that require intensive support. In contrast, the stability of single difficulties increased more steadily across the first four grades. This finding suggests that a single domain dysfluency in an early phase of skill development might stem from heterogeneous factors, including non cognitive deficits, such as lack of instruction or low motivation, that may be easier to target with educational support or interventions than, for example, a naming speed deficit. Overall, the findings imply that comorbid difficulties are generally stable, and rather than waiting until their scores have reached a certain cutoff point, systematic monitoring of skill development and increased support in reading and math are needed for those children who show early signs of risk for persistent fluency difficulties in both domains. 


\section{References}

Aro, M., \& Wimmer, H. (2003). Learning to read: English in comparison to six more regular orthographies. Applied Psycholinguistics, 24, 621-635. doi:10.1017/S0142716403000316

Aunola, K., \& Räsänen, P. (2007). The 3-minutes Basic Arithmetic Test. Unpublished. Badian, N.A. (1983). Dyscalculia and nonverbal disorders of learning. Progress in Learning Disabilities, 5, 235-264.

Branum-Martin, L., Fletcher, J.M., \& Stuebing, K.K. (2012). Classification and identification of reading and math disabilities: the special case of comorbidity. Journal of Learning Disability, 46, 490-499. doi: 10.1177/0022219412468767

Dirks, E., Spyer, G., van Lieshout, E.C, \& de Sonneville, L. (2008). Prevalence of combined reading and arithmetic disabilities. Journal of Learning Disabilities, 41.460-473. doi: $10.1177 / 0022219408321128$

Fuchs, L. S., Powell, S. R., Seethaler, P. M., Fuchs, D., Hamlett, C. L., Cirino, P. T. \& Fletcher, J. M. (2010). A framework for remediating number combination deficits. Council for Exceptional Children, 76, 135-156. doi: 10.1177/001440291007600201

Fuchs, L.S., Fuchs, D, \& Prentice, K. (2004). Responsiveness to mathematical problemsolving instruction: Comparing students at risk of mathematics disability with and without risk of reading disability. Journal of Learning Disabilities, 37, 293-310. doi: $10.1177 / 00222194040370040201$

Geary, D. C. (1993). Mathematical disabilities: Cognitive, neuropsychological, and genetic components. Psychological Bulletin, 114, 345-362.

Jordan, N.C., Kaplan, D., \& Hanich, L.B. (2002). Achievement growth in children with learning difficulties in mathematics: Findings of a two-year longitudinal study. Journal of Educational Psychology, 94, 586-597. doi:10.1037//0022-0663.94.3.586 
Koerte, I.K., Willems, A., Muehlmann, M., Moll, K, Corner, S., Pixner, S. et al., \& Schulte-Körne, G. (2016). Mathematical abilities in dyslexic children: a diffusion tensor imaging study. Brain Imaging and Behavior, 10, 781-791. doi:10.1007/s11682015-9436-y

Koponen, T., Mononen, R., Räsänen, P., \& Ahonen, T. (2006). Basic numeracy in children with specific language impairment: Heterogeneity and connections to language. Journal of Speech, Language, and Hearing Research, 46, 1-16. doi:10.1044/1092$4388(2006 / 005)$

Landerl, K., \& Moll, K. (2010). Comorbidity of learning disorders: prevalence and familial transmission. Journal of Child Psychology and Psychiatry, 51, 287-294. doi: 10.1111/j.1469-7610.2009.02164.x

Landerl, K., Göbel, S., \& Moll, K. (2013). Core deficit and individual manifestations of developmental dyscalculia (DD): The role of comorbidity. Trends in Neuroscience and Education, 2, 38-42. doi: 10.1016/j.tine.2013.06.002

Lerkkanen, M.-K., Niemi, P., Poikkeus, A.-M., Poskiparta, M., Siekkinen, M., \& Nurmi, J.-E. (2006). The First Steps Study [Alkuportaat], ongoing. Finland: University of Jyvaskyla.

Lerkkanen, M.-K., \& Poikkeus, A.-M. (2008). Luetun ymmärtämisen ryhmätesti: lausetaso [The group test of sentence level reading comprehension]. Unpublished test material. University of Jyväskylä.

Lewis, C., Hitch, G.J., \& Walker, P. (1994). The prevalence of specific arithmetic difficulties and specific reading difficulties in 9-to 10-year-old boys and girls. Journal of Child Psychology and Psychiatry, 35, 283-292.

Lin, Y., Morgan, P.L., Hillemeier, M.M, Cook, M., Maczuga, S., \& Farkas, G. (2013). Reading, mathematics and behavioral difficulties interrelate: Evidence from a cross- 
lagged panel design and population-based sample of US upper elementary students. Behavioral Disorders, 38, 212-227. doi: 10.1177/019874291303800404

Metsäpelto, R-L., Pakarinen, E., Kiuru, N. Poikkeus, A-M., Lerkkanen, M-K., \& Nurmi, J-E (2015). Developmental dynamics between children's externalizing problems, taskavoidant behavior, and academic performance in early school years: A 4-year followup. Journal of Educational Psychology, 107, 246-257. doi: 10.1037/a0037389

Morgan, P.L., Farkas, G., Hillemeier, M.M., \& Maczuga, S. (2016). Science achievement gaps begin very early, persist, and are largely explained by modifiable factors. Educational Researcher, 45, 18-35. doi: 10.3102/0013189X16633182

Murphy, M. M., Mazzocco, M. M. M., Hanich, L. B., \& Early, M. C. (2007). Cognitive characteristics of children with mathematics learning disability (MLD) vary as a function of the cutoff criterion used to define MLD. Journal of Learning Disabilities, 40, 458-478. doi: 10.1177/00222194070400050901

Murray, C., Goldstein, D.E, Nourse, S., \& Edgar, E. (2000). The postsecondary school attendance and completion rates of high school graduates with learning disabilities. Learning Disabilities Research \& Practice, 15, 119-127. doi: 10.1207/SLDRP1503_1

National Board of Education (NBE). (2004). National Core Curriculum for Basic Education 2004, Vammala, Finland.

PISA 2015. www.oecd.org/pisa.

Pikulski, J.J., \& Chard, D. J. (2005). Fluency: Bridge between decoding and reading comprehension. The Reading Teacher, 58, 510-519. doi: 10.1598/RT.58.6.2

Powell, S. R., Fuchs, L. S., Fuchs, D., Cirino, P., \& Fletcher, J. M. (2009). Effects of fact retrieval tutoring on third-grade students with math difficulties with and without reading difficulties. Learning Disabilities Research \& Practice, 15, 119-127. doi: 10.1207/SLDRP1503_1 
Seymour, P. H. K., Aro, M., \& Erskine, J. (2003). Foundation literacy acquisition in European orthographies. British Journal of Psychology, 94, 143-174. doi: $10.1348 / 000712603321661859$

Waber, D. P., Wolff, P. H., Forbes, P. W., \& Weiler, M. D. (2000). Rapid automatized naming in children referred for evaluation of heterogeneous learning problems: How specific are naming speed deficits to reading disabilities? Child Neuropsychology, 6, 251-261. doi:10.1076/chin.6.4.251.3137

Wagner, R. K., Torgesen, J. K., Rashotte, C. A., \& Pearson, N. A. (2009). TOSREC: Test of silent reading efficiency and comprehension. Austin, TX: Pro-Ed.

Wilson, E. B. (1927). Probable inference, the law of succession, and statistical inference. Journal of the American Statistical Association 22, 209-212. doi:10.1080/01621459.1927.10502953

Wolf, M., \& Bowers, P.G. (1999). The double-deficit hypothesis for the developmental dyslexias. Journal of Educational Psychology, 91, 415-438. doi: 10.1037/00220663.91 .3 .415

Vukovic, R.K., \& Siegel, L.S. (2010). Academic and cognitive characteristics of persistent mathematics difficulty from first through fourth grade. Learning Disabilities Research \& Practice, 25, 25-38. doi:10.1111/j.1540-5826.2009.00298 
Table 1

Summary of Previous Studies Examining Comorbidity in Reading and Math Skills

\begin{tabular}{|c|c|c|c|c|c|c|c|c|}
\hline Year & Authors & $\begin{array}{l}\text { Sample size } \\
\text { (language) }\end{array}$ & Age & Cutoff & Math measure & Reading measure & $\mathrm{RD}$ of $\mathrm{MD}$ & MD of RD \\
\hline 1994 & Lewis et al. & $\begin{array}{l}\text { 1,206 } \\
\text { (English) }\end{array}$ & $9-10$ & $-1 \mathrm{SD}^{\mathrm{a}}$ & $\begin{array}{l}\text { Combined fluency and } \\
\text { accuracy of arithmetic } \\
\text { weighted math test }\end{array}$ & $\begin{array}{l}\text { Accuracy of word } \\
\text { reading and } \\
\text { completion of } \\
\text { sentences (silent) }\end{array}$ & $64 \%$ & $37 \%$ \\
\hline 2008 & Dirks et al. & $\begin{array}{l}799 \\
\text { (Dutch) }\end{array}$ & $8-12$ & $-.67 \mathrm{SD}^{\mathrm{b}}$ & Accuracy of arithmetic & $\begin{array}{l}\text { Fluency of word } \\
\text { reading (oral) }\end{array}$ & $43 \%$ & $28 \%$ \\
\hline \multirow[t]{2}{*}{2010} & $\begin{array}{l}\text { Landerl \& } \\
\text { Moll }\end{array}$ & $\begin{array}{l}2,586 \\
\text { (German) }\end{array}$ & $8-10$ & $-1 \mathrm{SD}$ & Fluency of arithmetic & $\begin{array}{l}\text { Fluency of } \\
\text { sentence reading } \\
\text { (silent) }\end{array}$ & $39 \%$ & $37 \%$ \\
\hline & & & & $-1.5 \mathrm{SD}$ & & & $23 \%$ & $26 \%$ \\
\hline \multirow[t]{3}{*}{2014} & Moll et al. & $\begin{array}{l}1,633 \\
(\text { German })\end{array}$ & $9-10$ & $-1 \mathrm{SD}$ & Fluency of arithmetic & $\begin{array}{l}\text { Fluency of } \\
\text { sentence reading } \\
\text { (silent) }\end{array}$ & $41 \%$ & $34 \%$ \\
\hline & & & & $-1.25 \mathrm{SD}$ & & & $33 \%$ & $25 \%$ \\
\hline & & & & $-1.5 \mathrm{SD}$ & & & $31 \%$ & $22 \%$ \\
\hline
\end{tabular}

Note. $\mathrm{SD}=$ standard deviation. $\mathrm{RD}=$ reading difficulties. $\mathrm{MD}=$ math difficulties. ${ }^{\mathrm{a}}=$ the original study reported a standard score of $85(\mathrm{M}=100$ and $\mathrm{SD}=15)$ as the cutoff criterion. ${ }^{b}$ $=$ the original study reported a 25 percentile score as the cutoff criterion. 
Table 2

Descriptive Statistics for the Measures of Math and Reading Fluency

\begin{tabular}{crrrrrrrr}
\hline \hline & N & Min & Max & Median & Mean & SD Skewness & kurtosis \\
$\begin{array}{c}\text { Math fluency } \\
\text { Grade 1 }\end{array}$ & 1928 & 0 & 28 & 10.00 & 10.61 & 4.11 & 0.34 & 0.28 \\
2 & 1906 & 0 & 28 & 16.00 & 16.13 & 4.89 & -0.1 & -0.44 \\
3 & 1927 & 0 & 28 & 20.00 & 19.65 & 4.61 & -0.65 & 0.48 \\
4 & 1873 & 0 & 27 & 17.00 & 17.08 & 4.10 & -0.65 & 0.88
\end{tabular}

Sentence reading fluency

\begin{tabular}{crrrrrrrr} 
Grade 1 & 1927 & 0 & 46 & 17.00 & 18.05 & 8.12 & 0.38 & 0.01 \\
2 & 1902 & 0 & 60 & 31.00 & 30.00 & 8.50 & -0.07 & 0.26 \\
3 & 1922 & 6 & 60 & 38.00 & 38.12 & 8.74 & -0.07 & 0.24 \\
4 & 1874 & 2 & 60 & 46.00 & 45.51 & 9.29 & -0.52 & 0.5 \\
\hline
\end{tabular}


Table 3

Prevalence Estimates and Observed/Expected Ratios for Comorbid Fluency Difficulties

\begin{tabular}{lcccc}
\hline & \multicolumn{2}{c}{$\begin{array}{c}\text { Low/very low - Low/very low } \\
\text { (at or below 16\% in both) }\end{array}$} & \multicolumn{2}{c}{$\begin{array}{c}\text { Very low - Very low } \\
\text { (at or below 7\% in both) }\end{array}$} \\
Grade & \multicolumn{1}{c}{ \% } & O/E & O/E & 4.7 \\
\hline $1^{\text {st }}$ & $39 / 42 \%$ & 2.6 & $28 / 29 \%$ & 4.6 \\
$2^{\text {nd }}$ & $41 / 46 \%$ & 2.7 & $27 / 32 \%$ & 4.9 \\
$3^{\text {rd }}$ & $43 / 44 \%$ & 2.9 & $36 / 37 \%$ & 5.4 \\
$4^{\text {th }}$ & $35 / 40 \%$ & 2.3 & $36 \%$ & \\
\hline
\end{tabular}

Note. The confidence interval (CI. Wilson score interval. 1927) for prevalence rates at the $95 \%$ confidence level varied between $7 \%$ and $9 \%$. In both reading and math measures absolute cut-off point varied around $7^{\text {th }}$ percentile and 16th percentile causing in a most of the cases two percentages for comorbidity. $\mathrm{O} / \mathrm{E}=$ observed/expected ratio. 
Table 4

Prevalence Estimates of Comorbid Dysfluency Difficulties in Cases of Low vs. Very Low

Performance in Math $(M)$ or Reading $(R)$

\begin{tabular}{lcc|cc}
\hline & $\begin{array}{c}\text { low M- low/very low R } \\
(7-16 \%-\text { below 16\%) }\end{array}$ & $\begin{array}{c}\text { very low M- low/very low R } \\
\text { (below 7\% - below 16\%) }\end{array}$ & $\begin{array}{c}\text { low R- low/ very low M } \\
(7-16 \%-\text { below 16\%) }\end{array}$ & $\begin{array}{c}\text { very low R - low/very low M } \\
\text { (below 7\% - below 16\%) }\end{array}$ \\
Grade & $\%$ & $\%$ & $\%$ & $\%$ \\
\hline 1st & $38 \%$ & $50 \%$ & $32 \%$ & $50 \%$ \\
2 2nd & $40 \%$ & $57 \%$ & $38 \%$ & $54 \%$ \\
3 rd & $35 \%$ & $51 \%$ & $31 \%$ & $55 \%$ \\
4 th & $30 \%$ & $52 \%$ & & \\
\hline
\end{tabular}

Note. $\mathrm{M}=$ math; $\mathrm{R}=$ reading; Very low $=$ children with a score $\leq 7 \%$ in the respective skill; Low $=$ children with a score between $7-16 \%$. Low/very low $=$ children with a score $\leq 16 \%$. 
Table 5

Stability of Comorbid and Single Dysfluency Difficulties in Math and Reading

\begin{tabular}{|l|l|l|l|l|}
\hline Grade & 2nd & & & \\
\hline 1st & TA & $\begin{array}{c}\text { MD- } \\
\text { profile }\end{array}$ & $\begin{array}{l}\text { RD- } \\
\text { profile }\end{array}$ & $\begin{array}{l}\text { MD/RD - } \\
\text { profile }\end{array}$ \\
\hline TA & $\mathbf{8 7 \%}$ & $5 \%$ & $6 \%$ & $1 \%$ \\
\hline MD & $48 \%$ & $\mathbf{2 3} \%$ & $12 \%$ & $13 \%$ \\
\hline RD & $27 \%$ & $5 \%$ & $\mathbf{4 2} \%$ & $23 \%$ \\
\hline MD \& RD & $9 \%$ & $18 \%$ & $21 \%$ & $\mathbf{4 1 \%}$ \\
\hline
\end{tabular}

\begin{tabular}{|l|l|l|l|l|}
\hline Grade & 3rd & & & \\
\hline 2nd & TA & $\begin{array}{c}\text { MD- } \\
\text { profile }\end{array}$ & $\begin{array}{l}\text { RD- } \\
\text { profile }\end{array}$ & $\begin{array}{l}\text { MD/RD- } \\
\text { profile }\end{array}$ \\
\hline TA & $\mathbf{8 7 \%}$ & $6 \%$ & $5 \%$ & $0 \%$ \\
\hline MD & $35 \%$ & $\mathbf{4 3} \%$ & $6 \%$ & $16 \%$ \\
\hline RD & $27 \%$ & $2 \%$ & $\mathbf{4 6 \%}$ & $19 \%$ \\
\hline MD \& RD & $5 \%$ & $3 \%$ & $16 \%$ & $\mathbf{7 3 \%}$ \\
\hline
\end{tabular}

\begin{tabular}{|l|l|l|l|l|}
\hline Grade & 4th & & & \\
\hline 3rd & TA & $\begin{array}{c}\text { MD- } \\
\text { profile }\end{array}$ & $\begin{array}{l}\text { RD- } \\
\text { profile }\end{array}$ & $\begin{array}{l}\text { MD/RD - } \\
\text { profile }\end{array}$ \\
\hline TA & $\mathbf{8 9 \%}$ & $7 \%$ & $4 \%$ & $0 \%$ \\
\hline MD & $28 \%$ & $\mathbf{6 2 \%}$ & $5 \%$ & $5 \%$ \\
\hline RD & $14 \%$ & $6 \%$ & $\mathbf{5 9 \%}$ & $14 \%$ \\
\hline MD \& RD & $4 \%$ & $12 \%$ & $8 \%$ & $\mathbf{7 3 \%}$ \\
\hline
\end{tabular}

\begin{tabular}{|l|l|l|l|l|}
\hline Grade & 4th & & & \\
\hline 2nd & TA & $\begin{array}{c}\text { MD- } \\
\text { profile }\end{array}$ & $\begin{array}{l}\text { RD- } \\
\text { profile }\end{array}$ & $\begin{array}{l}\text { MD/RD - } \\
\text { profile }\end{array}$ \\
\hline TA & $\mathbf{8 6 \%}$ & $8 \%$ & $4 \%$ & $1 \%$ \\
\hline MD & $46 \%$ & $\mathbf{3 9 \%}$ & $11 \%$ & $5 \%$ \\
\hline RD & $29 \%$ & $6 \%$ & $\mathbf{4 6 \%}$ & $14 \%$ \\
\hline MD \& RD & $5 \%$ & $5 \%$ & $16 \%$ & $\mathbf{6 8 \%}$ \\
\hline
\end{tabular}

Note. $\mathrm{MD}=$ Math difficulties; $\mathrm{RD}=$ reading difficulties; $\mathrm{TA}=$ typically achieving 
$\mathbf{o}=$ Below 7th percentile in both skills at 1st grade
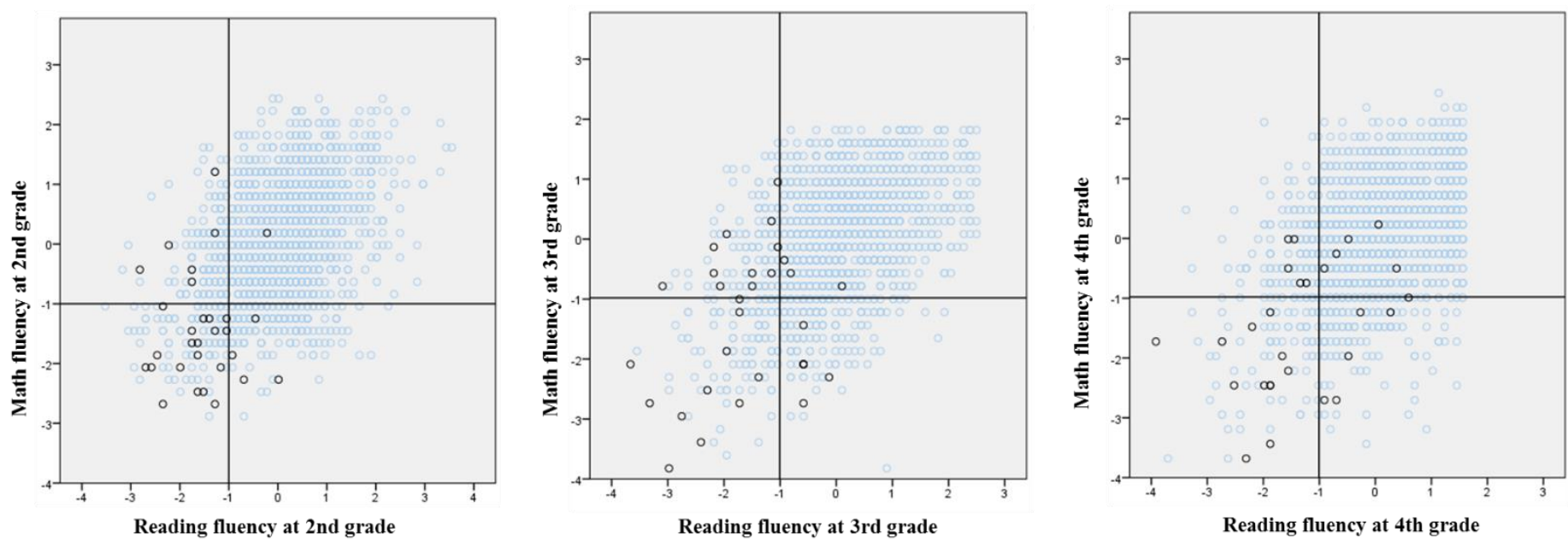

$\mathbf{o}=$ Below 7th percentile in both skills at 2nd grade
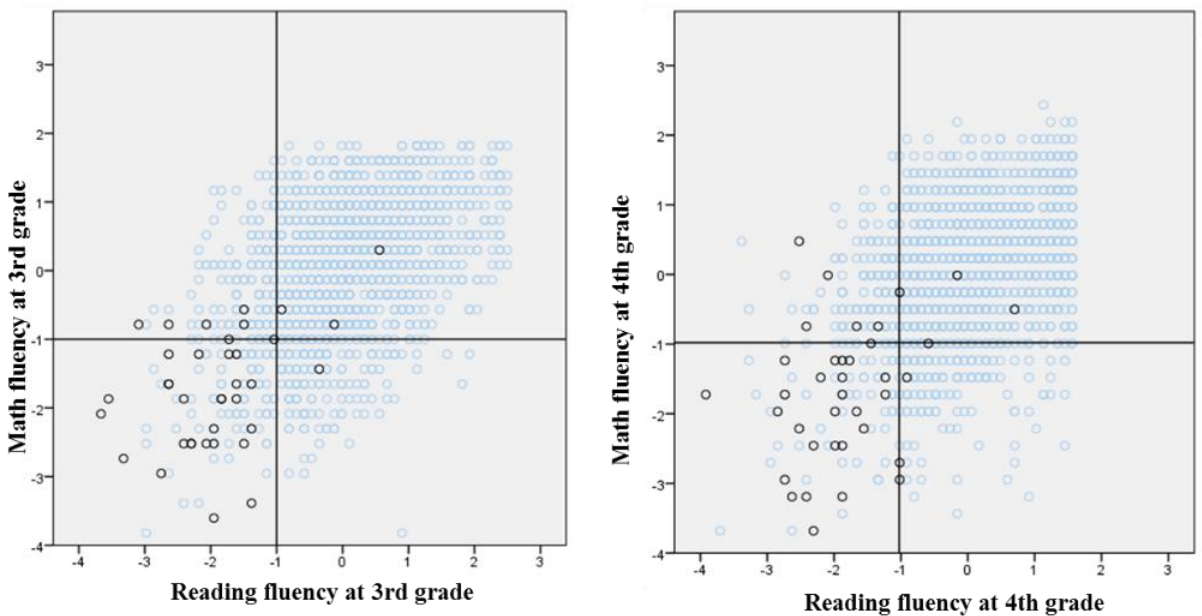

$\mathbf{0}=$ Below 7 th percentile in both skills at 3rd grade

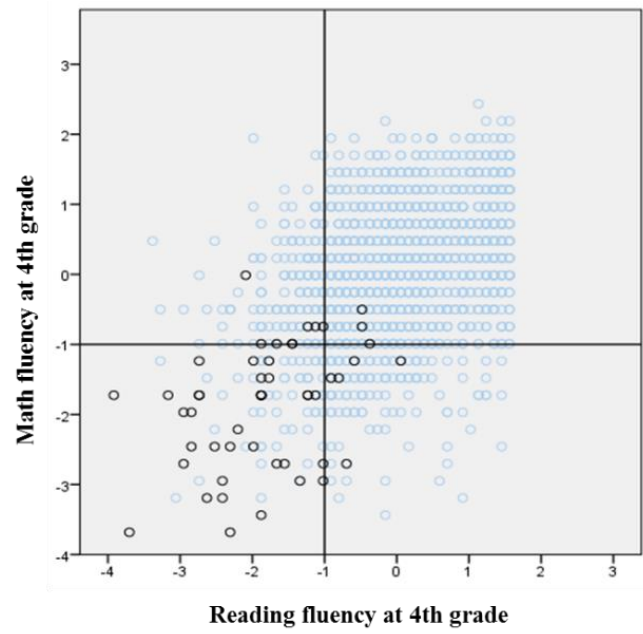

Figure 1. Stability and Change of Comorbid Difficulties in Math and Reading 
- Comorbid fluency difficulties in reading and math were more stable than single difficulties.

- Stability of difficulties increased across Grades 1 to 4.

- Very poor performance in one skill domain co-occurred with difficulties in the other domain with $50 \%$ probability.

- Comorbid difficulties showed higher prevalence rates in Grades 3 and 4 as opposed to Grades 1 and 2. 